\title{
SPECTROPHOTOMETRIC MONITORING OF BIOFOULING
}

\author{
Liesel Jacobs, Elize E. De Bruyn and Thomas E. Cloete
}

\section{INTRODUCTION}

Microorganisms attach to surfaces in order to survive (Cloete et al, 1992). This was first suggested by Heukelakiam and Heller (1940) as well as Zobell (1943) who found that bacteria can grow more readily, at low organic nutrient concentration, after attachment to available surfaces, presumably because adsorbed nutrients are concentrated and thus more accessible. This attachment leads to the development of microbial biofilms (Costerton and Lappin-Scott, 1989), causing serious fouling problems in many aquatic systems. In industrial water systems biofouling may cause serious financial losses by inducing metal corrosion and resulting in energy losses (Costerton and Lappin-Scott, 1989). The monitoring of biofilm formation has therefore become a well-studied field (McCoy et al, 1981; Eigmy et al., 1983; Bakke and Olsson, 1986; Challinor, 1991). However, methods currently in use to detect and quantify biofouling in industrial water systems have severe limitations.

In recent years the monitoring of biofouling shifted from the determination of planktonic bacterial numbers to that of sessile bacterial counts (Cloete et al., 1992). This was mostly because planktonic bacterial numbers may underestimate or overestimate the extent of the problem.

Devices such as the Robbins device (McCoy et al., 1981) and the Pedersen device (Pedersen, 1982) have proven useful in the study of undisturbed portions of biofilm. Unfortunately these techniques rely on the culturing of the organisms after removal of the biofilm from the metal studs, or scanning electron microscopy (SEM) investigations of the biofilm (Brozel 1990; Costerton et al, 1987). Counting bacteria by making use of culture media is not only time-consuming, but the composition of a single culture medium cannot support the growth of the diversity of bacterial species involved in biofouling. A lot of expertise and sophisticated equipment are needed to obtain results with SEM techniques, as well as Image analysis and Confocal Laser Microscopy, that give 3-D images of biofilms (Coldwell and Lawrence, 1989). These highly sophisticated methods are not suitable for routine monitoring of biofilms.

More recently, Wolfaardt et al. (1991) described the use of DAPI (4,6 - diamidino - z - phenylidole) to quantify sessile bacteria. Direct counting of DAPI-stained cells gave more realistic and reliable estimations of biofouling than culturing techniques. The method is also relatively easy to perform. Although the use of DAPI offers a number of advantages over conventional culturing techniques, it also has limitations. The samples must be stained and counted under the microscope. This is a time-consuming exercise. Results are therefore not immediately available. After treatment the samples cannot be used for further studies.

The major drawback of currently used techniques to study biofouling is that bacteria numbers must be determined, whether on culture plates or under the microscope. In this study, we developed a spectrophotometric method to overcome these disadvantages. By using absorbance to determine biofouling we eliminated the need for culturing and counting of bacteria. This method was compared to the quantification of the attached cells by DAPI-staining and the scanning electron microscope. 


\section{MATERIALS AND METHODS}

\section{$\underline{\text { Organism used }}$}

A wild strain of Pseudomonas aeruginosa isolated from a cooling water system and identified in a previous study (Brozel and Cloete, 1992) was used.

\section{Continuous flow}

Through system. A modified Pedersen device (McCoy et al., 1981) and a flow-through tube were connected in series with a peristaltic pump, which in turn was connected to a 4 litre reservoir (Fig. 1). Pseudomonas aeruginosa was cultured in $200 \mathrm{ml} \mathrm{R} 2 \mathrm{~A}$ broth (Reasoner and Geldreich, 1985) for $24 \mathrm{~h}$ at room temperature. Of this culture 20 $\mathrm{ml}$ were used to inoculate the reservoir containing 4 litre R2A medium. The flow rate through the system was 1,8 $\mathrm{m} / \mathrm{h}$. Sterile medium was continuously fed into the reservoir at a dilution rate of $240 \mathrm{ml} / \mathrm{h}$. The same amount of used medium and cells left the reservoir, keeping the cells in the same growth phase at all times and ensuring a constant concentration of 108 cells $/ \mathrm{ml}$ in the reservoir and the flow-through system.

\section{The modified Pedersen device}

The modified Pedersen device was used because it allows the study of a relatively large surface area of undisturbed biofilm (Fig. 2). The following additional modifications were made: (1) The device was made from perspex, instead of steel, (2) coupons the size of microscope slides were used instead of microscope cover slips, (3) only one test pile was used, and (4) coupons were vertically installed instead of horizontally. Twenty 3CR12 metal coupons were held in place in the device. Coupons $75 \times 27 \times 1 \mathrm{~mm}$ in size were used for the DAPI-staining. Smaller coupons $(25 \times 27 \times$ $1 \mathrm{~mm}$ ) were used for the scanning electron microscopy studies. Before each experiment, the coupons were prepared as described by Wolfaardt et al. (1991). Prior to use, the device was cleaned with a soap solution, thoroughly rinsed, sterilized with $5 \%$ hydrogen peroxide for $10 \mathrm{~min}$. and flushed with sterile distilled water to remove any residues.

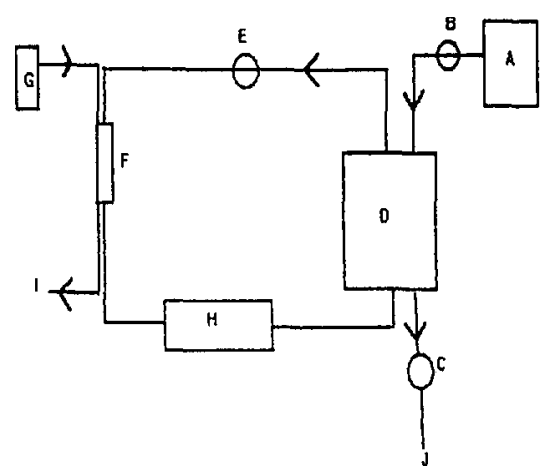

Fig. 1. Diagram of the Continuous flow-through system with (A) the sterile medium, (B), (C) and (E) peristaltic pumps, (D) the reservoir, $(F)$ the flow through glass tube, $(\mathrm{G})$ the sterile distilled water, $(\mathrm{H})$ the modified Pedersen device, and (I) and (J) the effluent. 


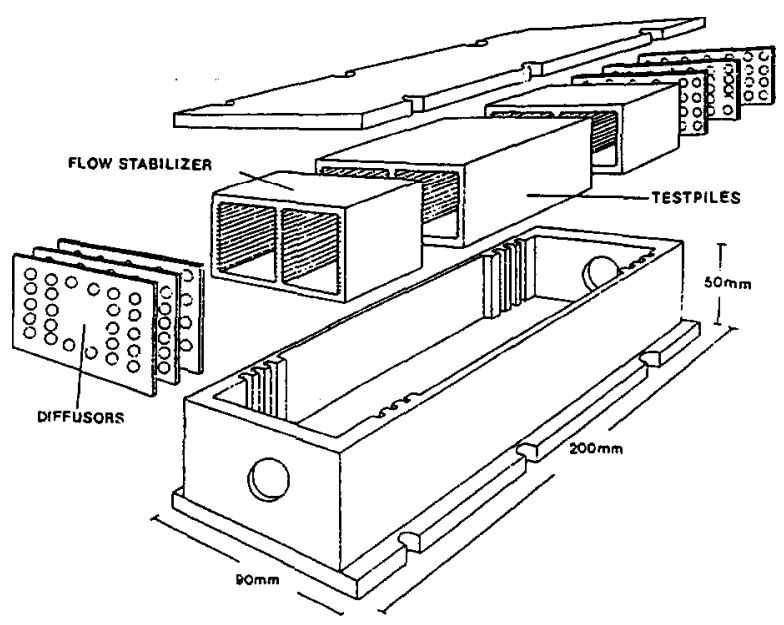

Fig. 2. The Pedersen Device.

The flow-through glass tube

A flow-through glass tube was constructed for the spectrophotometric analysis (Fig. 3). Before each experiment the tube was washed with a soap solution (Extran), rinsed with distilled water and dry sterilized in an oven for $6 \mathrm{~h}$ at $180^{\circ} \mathrm{C}$.

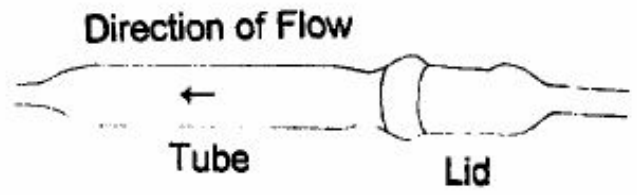

Fig. 3. The Flow-through glass tube. 

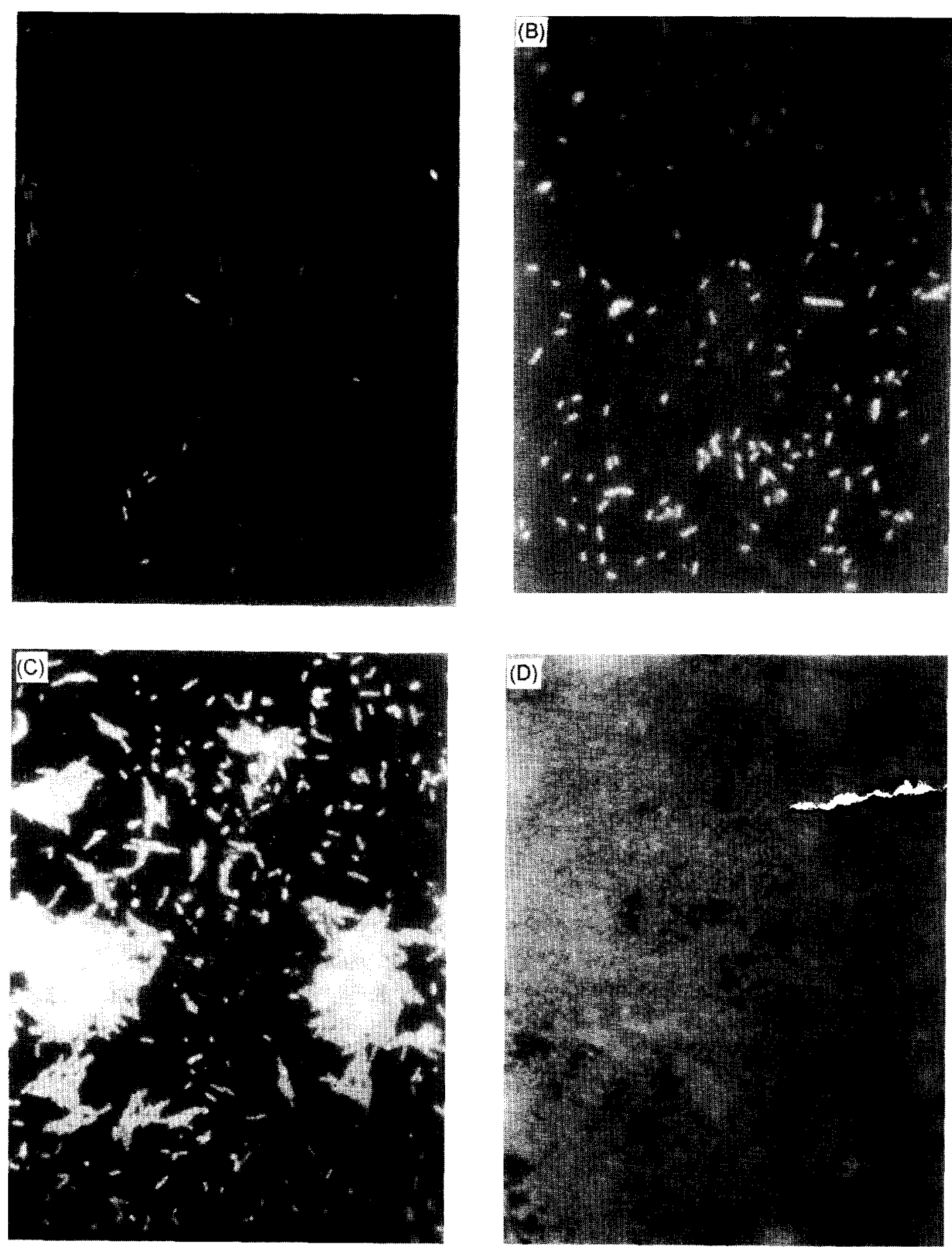

Fig. 4. DAPI-stained bacteria attached to 3 CR1 12 coupons, after (A) 4 h, (B) 8 h, (C) 24 h, with micro colony formation and (D) attachment after $48 \mathrm{~h}$, with bacteria adhering in layers to form a biofilm ( $800 \mathrm{X}$ magnification) 

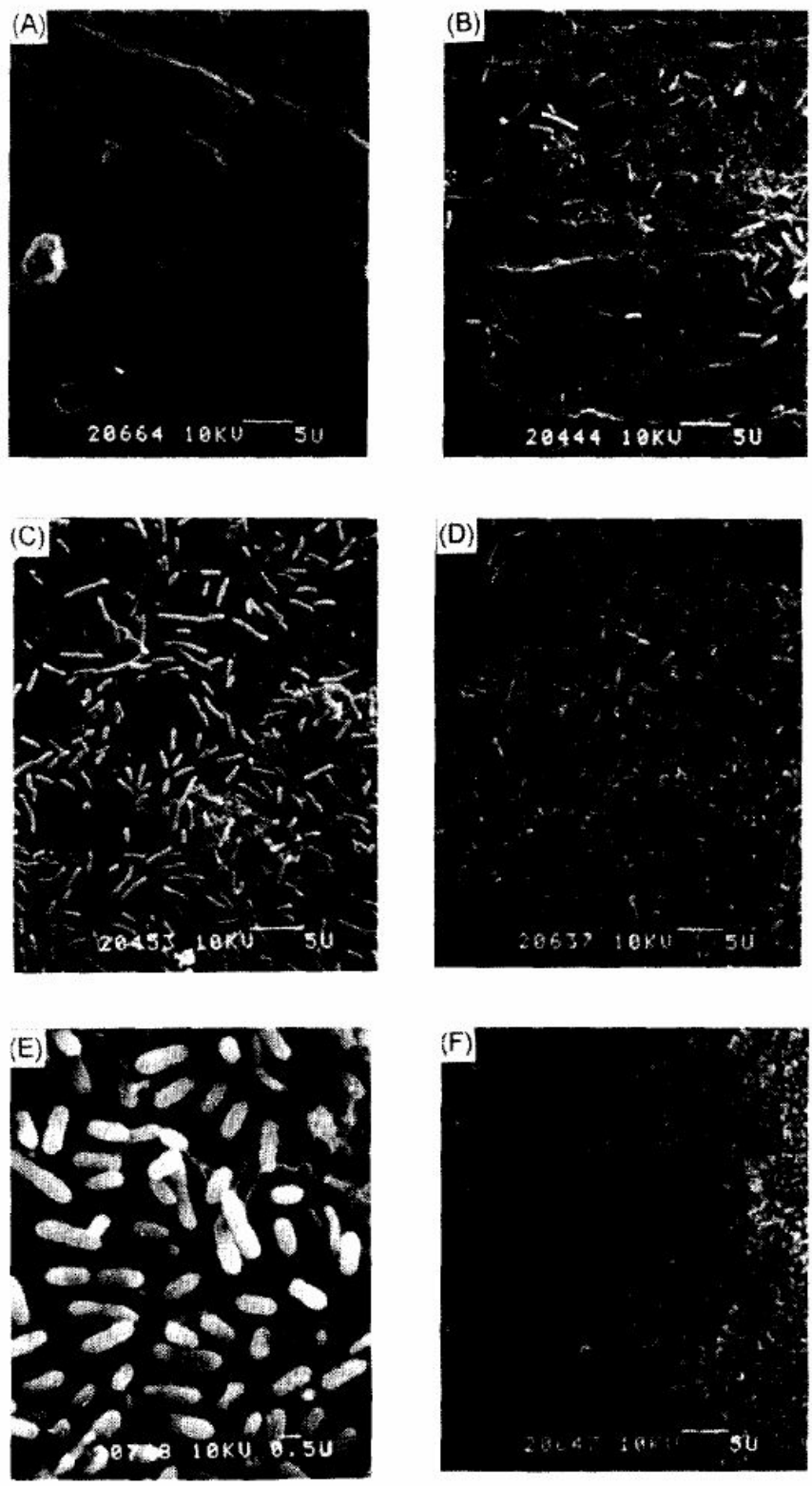

Fig. 5. SEM photomicrographs of attached $P$ s. aeruginosa: (A) the control with no bacterial adhesion, (B) the attachment after $4 \mathrm{~h},(\mathrm{C})$ after $8 \mathrm{~h}$, (D) $24 \mathrm{~h}$, (E) $24 \mathrm{~h}$ with EPS production and (F) after $48 \mathrm{~h}$. The bars represent 5 um for A, B, C, D and F and for $\mathrm{E}$ the bar represents $0,5 \mathrm{um}$. 
Coupons $(25 \times 27 \times 1 \mathrm{~mm})$ were removed, in duplicate, from the modified Pedersen device at 4, 8, 24, 28, 32, 48 and 56h, with a sterile forceps and replaced with a sterile coupon, in order to keep the flow constant. After removal the coupons were rinsed with sterile distilled water for 30 s to remove any unattached cells and then fixed for SEM by the following series of treatments: $2 \%$ glutaraldehyde ( 1 hour); $0.175 \mathrm{M}$ Phosphate- buffer ( $3 \times 15 \mathrm{~min}$.); $50 \%$ ethanol $(1 \mathrm{x} 15 \mathrm{~min}$.) ; 70\% ethanol $(1 \mathrm{x} 15 \mathrm{~min}$.); $90 \%$ ethanol $(1 \mathrm{x}$ $15 \mathrm{~min}$.) and $100 \%$ ethanol ( $3 \times 15 \mathrm{~min}$.). The coupons were thereafter dried in a critical-point dryer, mounted on studs and coated with gold plasma and examined using the Hitachi S-450 scanning electron microscope.

\section{Quantification of attached bacteria using 4.6-diamidino-z-phenylidole (DAPD}

The $75 \times 27 \times 1 \mathrm{~mm}$ coupons, removed from the Pedersen device and rinsed with sterile water as described for the SEM studies of biofilm formation, were stained with DAPI for epifluorescence microscopy (Wolfaardt et al., 1991). Attached bacteria were counted under oil immersion using an Epifluorescence microscope. Ten randomly chosen microscope fields were counted under the $800 \mathrm{x}$ magnification.

\section{$\underline{\text { Spectrophotometric measurements }}$}

An absorbance measurement of the bacteria attached to the glass tube was done simultaneously to the removal of the coupons from the modified Pedersen device. The SQ 118 Spectrophotometer, adjusted to a wavelength of $550 \mathrm{~nm}$, was used. Before each measurement, a zero adjustment was done on the spectrophotometer using a clean tube filled with distilled water. The absorbance of the bacteria attached to the flow-through tube was determined after carefully rinsing and replacing the medium in the tube with sterile distilled water.

\section{$\underline{\text { Statistical analysis }}$}

Linear regression analysis was performed on the results obtained in the quantification of biofilm formation over time, using the DAPI staining technique and direct spectrophotometric monitoring. Correlation coefficients were calculated for the different data sets. All the statistical analysis was in the $95 \%$ confidence interval.

\section{RESULTS}

Biofilm formation of Ps. aeruginosa on the modified Pedersen device coupons in a continuous flow-through system as determined by SEM studies and the DAPI staining technique is shown in Fig.4 and 5. Ps. aeruginosa started to adhere to the coupons within the first half hour of exposure to the bacteria, which is in accordance with the results of Stone and Zottola (1985). A typical increase in numbers is visible, up to the stage where the entire surface of the coupon is overgrown. The formation of micro colonies occurred after $24 \mathrm{~h}$ of exposure (Fig. $4 \mathrm{c}$ and $5 \mathrm{~d}$ ) and brought along the layering of cells, which resulted in the formation of a mature biofilm after $48 \mathrm{~h}$ (Fig. $4 \mathrm{~d}$ and 5f). The production of extracellular polysaccharides (EPS) could be seen as early as $24 \mathrm{~h}$ after exposure (Fig. $4 \mathrm{C}$ ). After $56 \mathrm{~h}$ a levelling off of the adhesion rate took place. The absorbance measurements of attached bacteria cells to the glass tube increased within the first $4 \mathrm{~h}$ after initiation of the experiment (Fig. 6). After $8 \mathrm{~h}$ the adhesion of bacteria on the glass surface could be seen with the naked eye.

The attachment rates of Ps. aeruginosa to the Pedersen device metal coupons as determined by DAPI total counts and to the glass tube surface as determined by direct absorbance measurements are shown in Figure 6. There was a linear relationship between the DAPI technique and time $\left(\mathrm{r}^{2}=0.944\right)$ as well as absorbance measurements and time $\left(r^{2}=0.927\right)$ in determining biofilm formation. 


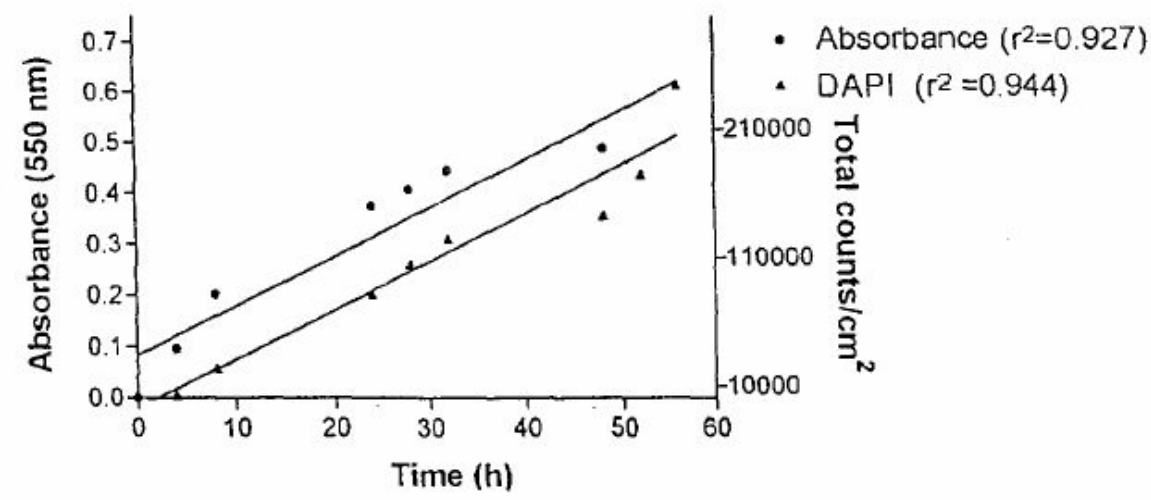

Fig. 6. Linear regression analysis of direct bacterial counts using the DAPI- technique and that of the absorbance measurements of attached Ps. aeruginosa cells $(550 \mathrm{~nm})$ over a period of $56 \mathrm{~h}$.

A linear relationship between the DAPI technique and direct absorbance measurements $\left(r^{2}=0.925\right)$ for biofilm formation monitoring was also demonstrated (Fig.7).

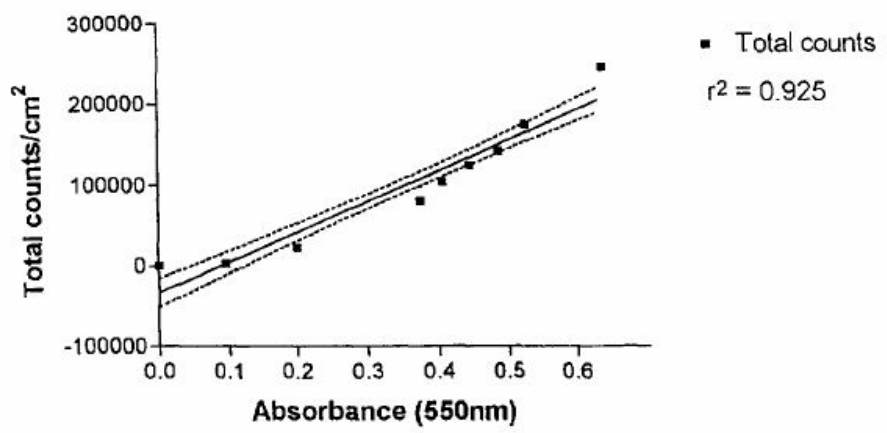

Fig. 7. Linear regression correlation between the DAPI-technique (total counts/cm2) and the absorbance $(550 \mathrm{~nm})$ of the attached Ps. aeruginosa cells.

\section{DISCUSSION}

The DAPI technique and absorbance measurements used in this study to quantify biofouling correlated in a linear fashion with time (Fig.6). The direct measurement of absorbance also correlated well with the total counts obtained using the DAPI technique $\left(r^{2}=0.925\right)$. Figure 7 demonstrates the linear relationship between the two techniques. Both these techniques therefore proved to be reliable for monitoring biofilm formation.

However, measuring absorbance in a glass tube is uncomplicated and an inexpensive method for obtaining reproducible results. Visual evaluation was also possible since the increase of attached bacteria could be seen with the naked eye. The advantages of using absorbance to measure the rate of colonization are therefore obvious: (1) results are immediately available for evaluation, which means that an immediate forecast can be done on the seriousness of biofouling, (2) no staining, counting or culturing needs to be done, (3) the glass tube can be used in more than one test, and (4) the biofilm can be used for further studies, such as species diversity and identification of attached bacteria. Another application for this technique would 
be the evaluation of biocide and biodispersant efficacy for the control of biofouling in the laboratory. The flow-through system can also possibly be installed and used as an online monitoring system in the field, for continuous monitoring of biofouling. This application, however, requires further investigation.

ACKNOWLEDGEMENTS This research was supported by a grant for research from the Water Research

Commission, South Africa.

\section{REFERENCES}

Bakke, R. and Olsson, P. Q. (1986). Biofilm thickness measurements by light microscopy. J.Microbial. Methods, 5,93-98.

Brözel, V. S. (1990). Aspects of bacterial biofouling control in water systems. MSc Thesis, University of Pretoria, South Africa.

Brözel, V. S.and Cloete, T. E. (1992). The effect of bactericide treatment on planktonic communities in water cooling systems. Water $S A, 18,87-92$.

Challinor, C. J. (1991). The monitoring and control of biofouling in industrial cooling water systems. Biofouling, 4, $253-263$.

Cloete, T. E., Brözel, V. S. and Von Holy, A. (1992). Practical aspects of biofouling control in industrial water systems. Int. Biodeterioration Biodegradation, 29, 299-341.

Coldwell, D. E.and Lawrence, J. R. (1989). Microbial growth and behaviour within surface microenvironment. Recent Advances in Microbial Ecology: Proceedings of the 5th international symposium on microbial ecology, pp. 140-145.

Costerton, J. W., Cheng, K-L., Geesey, G. G., Ladd, T. I., Nickel, J. C, Dasgupta, M. and Marrie, T. J. (1987). Bacterial biofilms in nature and disease. A. Rev. Microbiol, 41, 435-464.

Costerton, J. W. and Lappin-Scott, H. M. (1989). Behaviour of bacteria in biofilms. ASM News, 5, 650-654.

Eigmy, T. T., Maratea, D.and Bishop, P. L. (1983). Electron microscope examination of wastewater biofilm formation and structural components. Appl. Environ. Microbiol., 45,1921-1931.

Heukelakiam, H. and Heller, A. (1940). Relation between food concentration and surface for bacterial growth. J. Bacteriol, 40, 547-558.

McCoy, W. F., Bryers, J. D., Robbins, J. and Costerton, J. W. (1981). Observation of fouling biofilm formation. Can. J. Microbiol, 27, 910-917.

Pedersen, K. (1982). Method for studying microbial biofilms in flowing-water systems. Appl. Environ. Microbiol., 43, 6-13.

Reasoner, D. J. and Geldreigh, E. E. (1985). A new medium for the enumeration and subculture of bacteria from potable water. Appl. Environ. Microbiol, 49, 1-7.

Stone, L. S. and Zottola, E. A. (1985). Relationship between the growth phase of Pseudomonas fragi and its attachment to stainless steel. J. Food .Sci., 50, 957-960.

Wolfaardt, G. M, Archibald, R. E. M. and Cloete, T. E. (1991). The use of DAPI in the quantification of sessile bacteria on submerged surfaces. Biofouling, 4, 265-275.

Zobell, C. E. (1943). The effect of solid surfaces upon bacterial activity. J Bacteriol, 46, 39-56. 